\title{
Effect of the Hot Band Grain Size and Intermediate Annealing on the Deformation and Recrystallization Textures in Low Silicon Electrical Steels
}

\author{
Marcos F. de CAMPOS, Fernando J. G. LANDGRAF, ${ }^{1)}$ Rubens TAKANOHASHI, ${ }^{1)}$ Fabio C. CHAGAS, ${ }^{1)}$

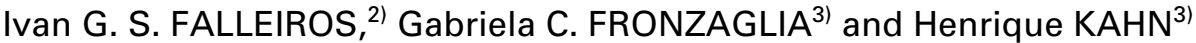 \\ Programa de Pós-Graduação em Engenharia Metalúrgica, EEIMVR, Universidade Federal Fluminense, Av. dos Trabalhadores, \\ 420 Vila Santa Cecília, 27255-125, Volta Redonda, RJ, Brasil. E-mail: mcampos@metal.eeimvr.uff.br \\ 1) Instituto de Pesquisas Tecnológicas do Estado de São Paulo, Brasil. \\ 2) Depto. de Engenharia Metalúrgica e de Materiais, Escola Politécnica, Universidade de São Paulo, Brasil. \\ 3) Depto. de Engenharia de Minas, Escola Politécnica, Universidade de São Paulo, Brasil.
}

(Received on August 12, 2003; accepted in final form on November 14, 2003)

\begin{abstract}
The effect of hot band grain size on the texture of low silicon steels was investigated. In spite of different hot band grain sizes $(22,125$ and $500 \mu \mathrm{m})$, the deformation texture is formed by the fibers $\langle 111\rangle / / \mathrm{ND}$ and $\langle 110\rangle / / R D$. Nevertheless the recrystallization texture is strongly affected. Increasing the hot band grain size, from 22 to $125 \mu \mathrm{m}$, the intensity of the Goss component in the recrystallized material increases and $\{111\}$ components decreases. The further increase to $500 \mu \mathrm{m}$ does not increase Goss, but increases cube on face component. When the hot band grain size is sufficiently large $(\sim 500 \mu \mathrm{m})$ the deformed grains tend to recrystallize independently, originating regions (clusters) of grains with same orientation. There is no apparent effect of an intermediate recovery (after deformation $\varepsilon=0.7$ annealing at $500^{\circ} \mathrm{C}$ during $1 \mathrm{~h}$ ) on the deformation or recrystallization textures.
\end{abstract}

KEY WORDS: electrical steels; texture; recrystallization; hot band grain size.

\section{Introduction}

Recently, several studies ${ }^{1-4)}$ have been focused on the investigation of hot band annealing as a useful method to improve the magnetic properties of non-oriented electrical steels. For instance, the data of Yashiki and Kaneko ${ }^{1)}$ shows that the hot band annealing increases magnetic permeability because the intensity of $\{110\}$ component increases when, at same time, the intensities of $\{111\}$ and $\{211\}$ components decrease, an effect often related ${ }^{5,6}$ to larger grain size of hot band.

Samples with hot band grain size on the order of $400 \mu \mathrm{m}$ show inhomogeneities in the cold rolled and recrystallized state. ${ }^{4,7,8)}$ Microstructural evidence indicates that each grain hardens differently, accumulates a different amount of ingrain shear bands, takes a different time to complete recrystallization, results a different final grain size and produces clusters of grains with similar orientations. ${ }^{7,8)}$

The hot band annealing has been mentioned for high $\mathrm{Si}$ steels. ${ }^{2)}$ In the case of low Si steels, the austenite to ferrite $(\gamma \rightarrow \alpha)$ transformation results in grain refinement. Thus, for low Silicon steels the maximum temperature for hot band annealing should be below $\operatorname{Ar}_{3}\left(T \approx 850^{\circ} \mathrm{C}\right.$ has been employed $^{1)}$ ).

Including an intermediate annealing in the course of rolling has also been used to change texture and control magnetic properties of electrical steels. The two stage rolling includes a recrystallization step, ${ }^{9)}$ but partial recrystallization $^{10)}$ or just recovery has been mentioned. ${ }^{11)}$

The objective of the present work is the investigation of the effects of a specific procedure of hot band annealing for low $\mathrm{Si}$ steels, aiming at large grain size by recrystallization at low temperatures $\left(\sim 800^{\circ} \mathrm{C}\right)$ after light deformation. This procedure has been mentioned by Hou. ${ }^{3}$ )

Besides presenting a systematic analysis of the effect of hot band grain size on the texture, the present study has the aim of including the effect of an intermediate recovery, during the cold rolling step, and evaluates their consequences on texture.

\section{Experimental}

This paper compares texture and microstructure of as deformed and recrystallized steel sheets produced from hot bands of different grain size $(22,125$ and $500 \mu \mathrm{m})$. These hot bands were cold rolled ( $\sim 80-90 \%$ reduction) with and without intermediate annealing.

The chemical composition of an experimental alloy with low silicon content is shown in Table 1. A $30 \mathrm{~mm}$ thick plate was hot rolled down to a $3.2 \mathrm{~mm}$ thick hot band, resulting in homogeneous grain size of $22 \pm 4 \mu \mathrm{m}$.

Grain sizes of 125 and $500 \mu \mathrm{m}$ at the hot band stage were 
Table 1. Chemical composition of the alloy.

\begin{tabular}{llllll}
\hline$\% \mathrm{Si}$ & $\% \mathrm{Al}$ & $\% \mathrm{Mn}$ & $\% \mathrm{P}$ & $\% \mathrm{~S}$ & $\% \mathrm{~N}$ \\
\hline 1.25 & 0.27 & 0.30 & $<0.01$ & 0.005 & 0.005 \\
\hline
\end{tabular}

obtained by slight cold rolling ( $\varepsilon=0.1$ and $\varepsilon=0.07$, respectively) followed by annealing at $800^{\circ} \mathrm{C}$ for $3 \mathrm{~h}$.

Intermediate annealing was performed after $\varepsilon=0.7$. To restrict microstructural change to recovery, annealing was done at $500^{\circ} \mathrm{C}$ for $1 \mathrm{~h}$. Total deformation amounts to $\varepsilon=1.5$ and $\varepsilon=2.1$.

The final annealing was done at $700^{\circ} \mathrm{C}$ for $5 \mathrm{~min}$ in a salt bath. The samples follow the denomination $(500 \mu \mathrm{m} / \varepsilon=$ 2.1) when just cold rolled or $(500 \mu \mathrm{m} / \varepsilon=2.1 / \mathrm{reX})$ after final annealing.

The crystallographic texture was evaluated at mid thickness by means of ODFs calculated from X-ray (110), (200), (211) pole figures obtained with $\operatorname{Co} \mathrm{K} \alpha$ radiation, under $32 \mathrm{kV}, 50 \mathrm{~mA}$ in a Philips X-Pert XRD diffractometer equipped with texture goniometer.

Optical microscopy was carried out after Nital $4 \%$ etching, for observation of grain boundaries and evidences of plastic deformation and in a three step etch for producing "etch pits". This etch consists of: immersion during $4 \mathrm{~s}$ in a solution with $70 \mathrm{~mL}$ of $\mathrm{H}_{2} \mathrm{O}+30 \mathrm{~mL} \mathrm{H}_{2} \mathrm{O}_{2}(30 \%)+5$ drops of $\mathrm{HCl}$, followed of immersion during $3 \mathrm{~s}$ in a solution with $70 \mathrm{~mL} \mathrm{H}_{2} \mathrm{O}+30 \mathrm{~mL} \mathrm{HCl}$, completed with a final immersion in Nital $4 \%$ during 10 a $30 \mathrm{~s}$, this one to reveal grain boundaries. Between the steps, the samples were dried in hot air.

\section{Results}

The effect of the amount of total deformation and of initial grain size on deformed texture can be seen in Figs. 1 to 3.

In the sample $(22 \mu \mathrm{m} / \mathcal{E}=1.5)$ (Fig. 1) we observe high intensity for the fibers $\langle 110\rangle / / \mathrm{RD}$ and $\langle 111\rangle / \mathrm{ND}$. There is a spreading around $\{211\}\langle 011\rangle$ and $\{100\}\langle 011\rangle$ (up to $\{100\}$ $\langle 023\rangle)$. The fiber $\langle 110\rangle / / \mathrm{RD}$ is incomplete, because there are no components $\{110\}\langle 110\rangle$. About the fiber $\langle 111\rangle / \mathrm{ND}$, we observe maximum intensity and spreading around $\{111\}$ $\langle 011\rangle$

Increasing deformation, sample $(22 \mu \mathrm{m} / \varepsilon=2.1)$ (Fig. 2) shows very similar results to those of sample (22 $\mu \mathrm{m} / \varepsilon=1.5)$ except for a small increase of the intensity of fiber $\langle 110\rangle / / \mathrm{RD}$ near $\{311\}\langle 011\rangle$.

The increase in grain size, sample $(500 \mu \mathrm{m} / \varepsilon=2.1)$ (Fig. 3 ), lead to similar results as sample $(22 \mu \mathrm{m} / \varepsilon=2.1)$ (Fig. 2), except a slightly higher intensity for fiber $\langle 111\rangle / / \mathrm{ND}$ in sample $(500 \mu \mathrm{m} / \varepsilon=2.1)$.

After recrystallization (note: both reX or RECRIST. are used in this text as abbreviation of recrystallized) the samples still present a $\langle 111\rangle / / \mathrm{ND}$ fiber, but the maximum is now on $\{111\}\langle 112\rangle$, as can be seen at Fig. 4 to $\mathbf{6}$. Besides that, sample $(22 \mu \mathrm{m} / \varepsilon=1.5 / \mathrm{reX})$ (Fig. 4) shows $\{032\}$ $\langle 100\rangle$ that is near to Goss, together with a not very strong $\{100\}\langle 011\rangle$. We emphasize the low intensity of all those texture components.

In the sample ( $125 \mu \mathrm{m} / \varepsilon=2.1$, reX) (Fig. 5), Goss is present, but with high intensity. We note some scattering

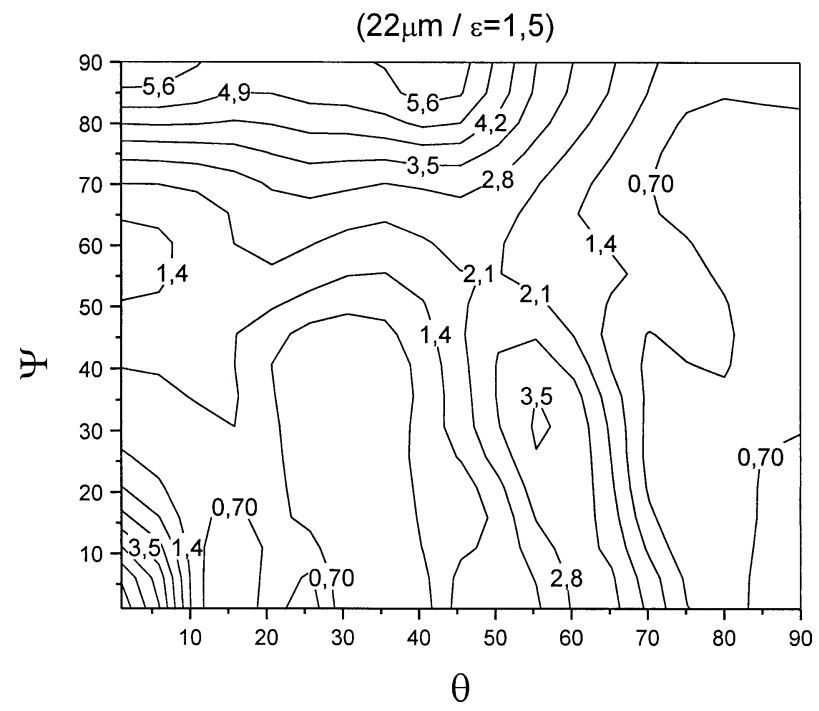

Fig. 1. Sample $(22 \mu \mathrm{m} / \varepsilon=1.5)$. ODF, section $\Phi=45^{\circ}$. Roe notation.

$(22 \mu \mathrm{m} / \varepsilon=2,1)$

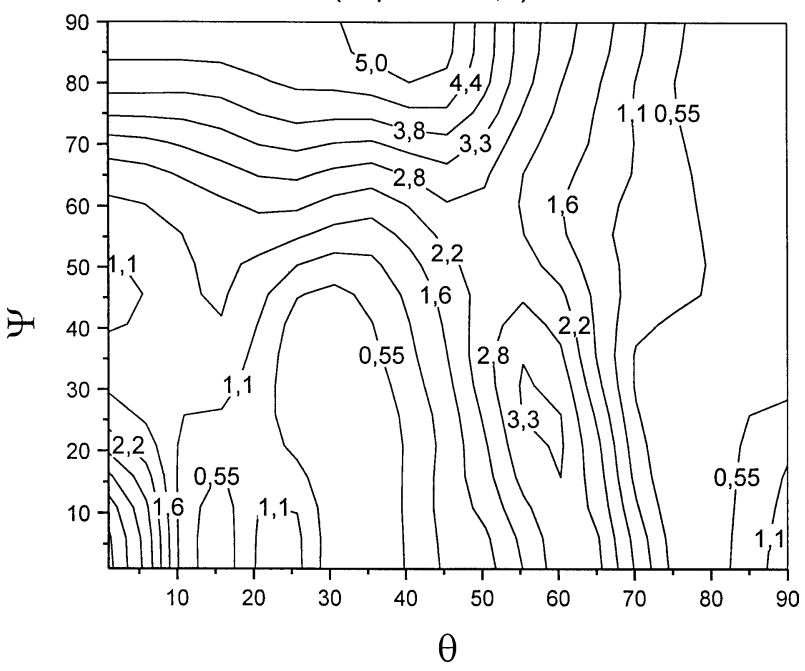

Fig. 2. Sample $(22 \mu \mathrm{m} / \varepsilon=2.1)$. ODF, section $\Phi=45^{\circ}$. Roe notation.

$(500 \mu \mathrm{m} / \varepsilon=2,1)$

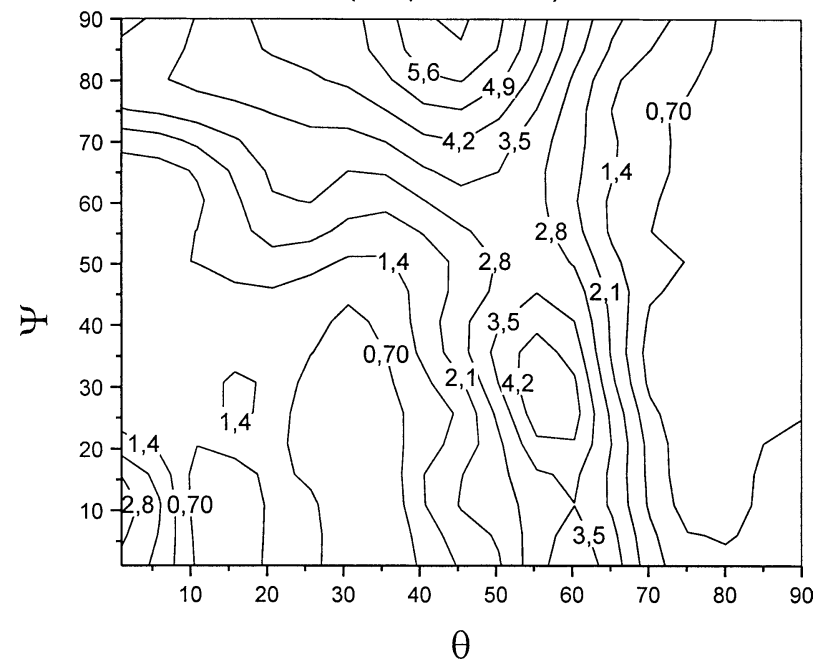

Fig. 3. Sample $(500 \mu \mathrm{m} / \varepsilon=2.1)$. ODF, section $\Phi=45^{\circ}$. Roe notation. 


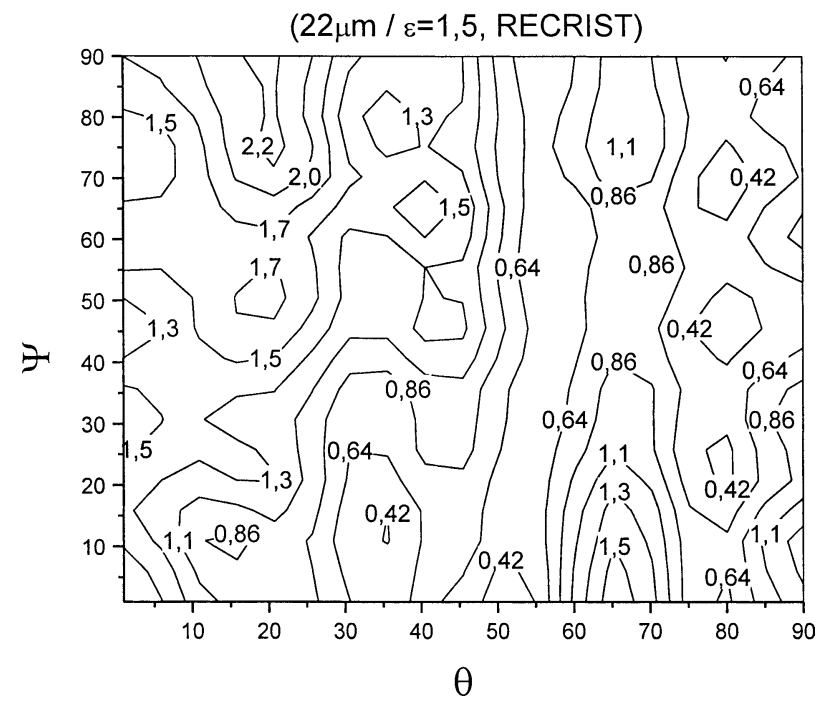

Fig. 4. Sample $(22 \mu \mathrm{m} / \varepsilon=1.5 / \mathrm{reX})$. ODF, section $\Phi=45^{\circ}$. Roe notation.

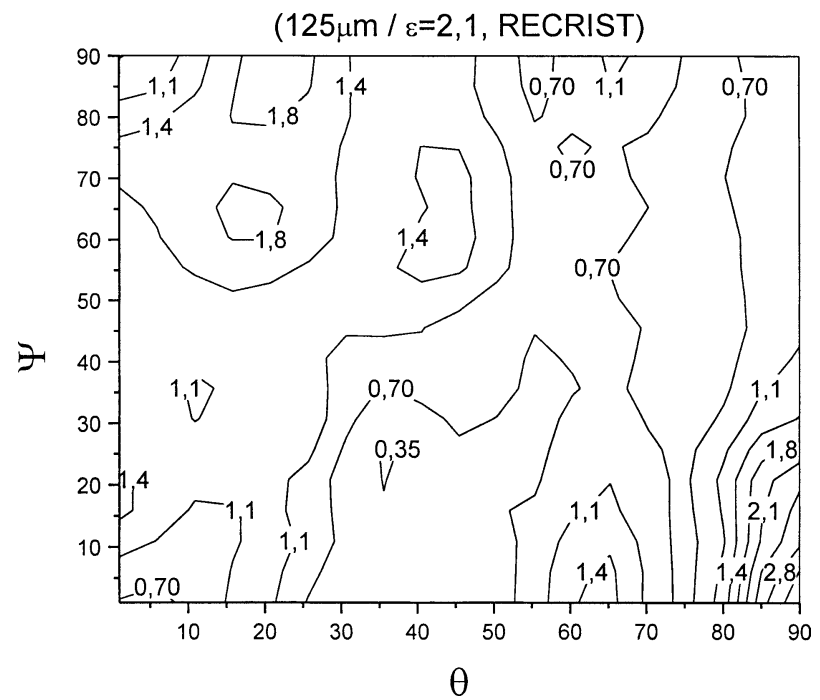

Fig. 5. Sample $\left(125 \mu \mathrm{m} / \mathcal{E}=2.1\right.$, reX). ODF, section $\Phi=45^{\circ}$. Roe notation.

$(500 \mu \mathrm{m} / \varepsilon=2,1, \mathrm{RECRIST})$

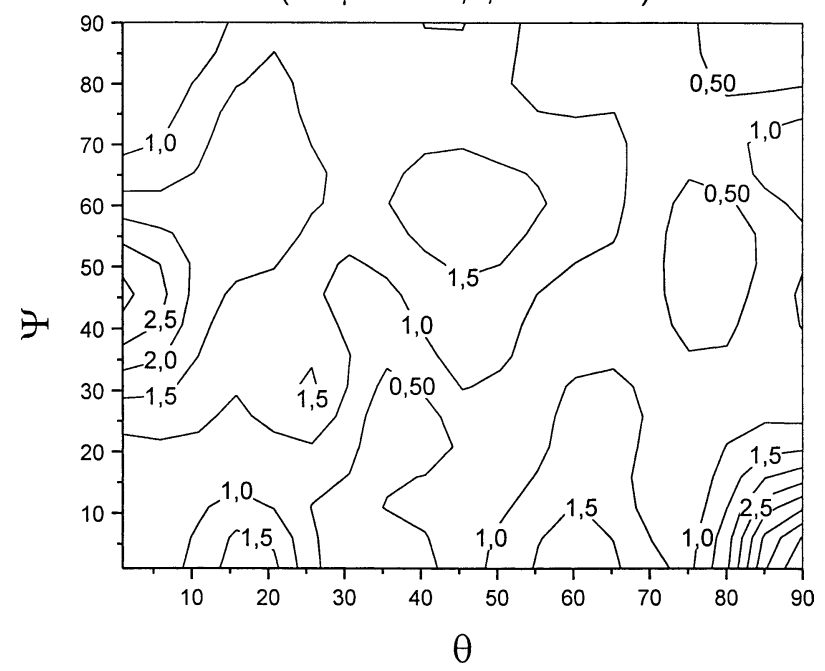

Fig. 6. Sample $(500 \mu \mathrm{m} / \varepsilon=2.1, \mathrm{reX})$. ODF, section $\Phi=45^{\circ}$. Roe notation. around Goss $\{110\}\langle 001\rangle$ and presence of $\{310\}\langle 001\rangle$.

The results of sample $(500 \mu \mathrm{m} / \varepsilon=2.1$, reX) (Fig. 6) are similar to those of sample $(125 \mu \mathrm{m} / \varepsilon=2.1$, reX) (Fig. 5), with the $\langle 111\rangle / / \mathrm{ND}$ fiber peaking at $\{111\}\langle 112\rangle$ and a very intense Goss. The main difference is the appearing of the cube-on-face $\{100\}\langle 001\rangle$.

The texture of the samples that received the intermediate recovery IR (after $\varepsilon=0.7$ ) is presented at the Figs. 7 to $\mathbf{1 2}$. The analysis of results has shown that the intermediate recovery IR was not effective for changing deformation texture, nor the recrystallization texture.

The texture of sample $(22 \mu \mathrm{m} / \varepsilon=2.1 /$ IR) (Fig. 7) is very similar to that of $(22 \mu \mathrm{m} / \varepsilon=2.1)$ (Fig. 2). We observe high intensity for the fiber $\langle 110\rangle / / \mathrm{RD}$ and the fiber $\langle 111\rangle / / \mathrm{ND}$. In the case of fiber $\langle 111\rangle / / \mathrm{ND}$, the maximum intensity is around $\{111\}\langle 011\rangle$.

In the same way, the texture of sample $(125 \mu \mathrm{m} / \varepsilon=$ 2.1/IR) (Fig. 8) is very similar to that of sample $(22 \mu \mathrm{m} / \varepsilon=$ 2.1) (Fig. 1) and, also, the texture of sample $(500 \mu \mathrm{m} / \varepsilon=$

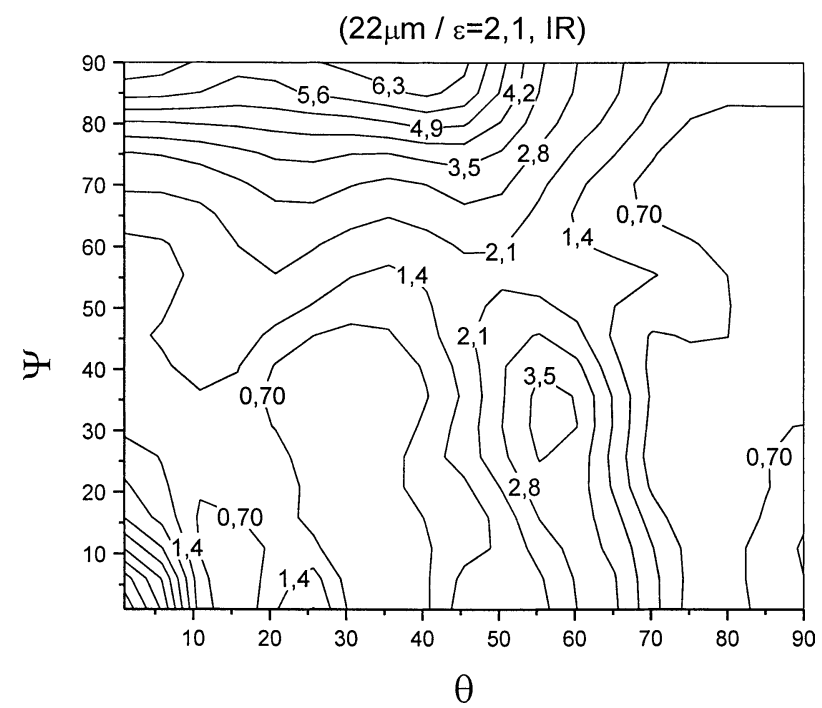

Fig. 7. Sample $(22 \mu \mathrm{m} / \varepsilon=2.1 / \mathrm{IR})$. ODF, section $\Phi=45^{\circ}$. Roe notation.

$(125 \mu \mathrm{m} / \varepsilon=2,1, \mathrm{IR})$

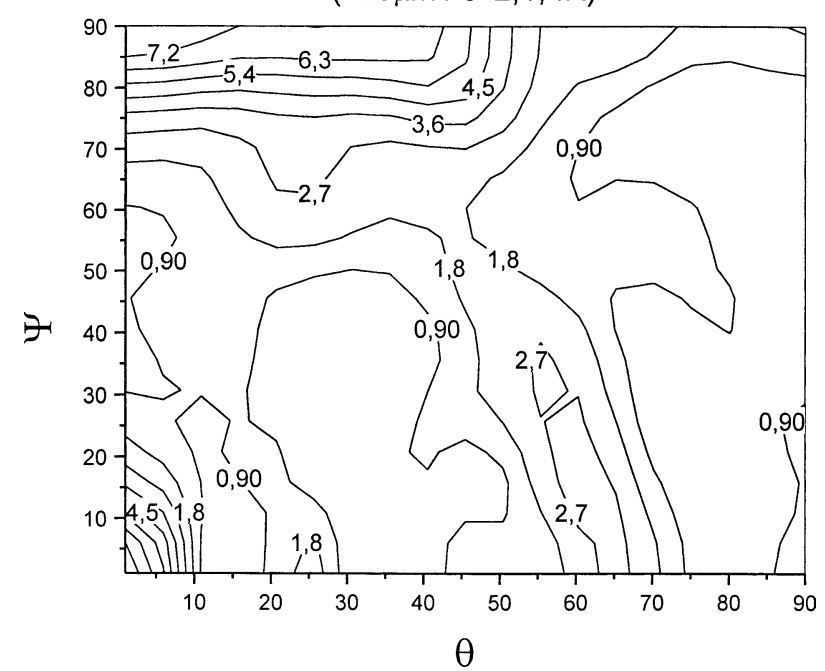

Fig. 8. Sample $(125 \mu \mathrm{m} / \varepsilon=2.1 / \mathrm{IR})$. ODF, section $\Phi=45^{\circ}$. Roe notation. 
$(500 \mu \mathrm{m} / \varepsilon=2,1, \mathrm{IR})$

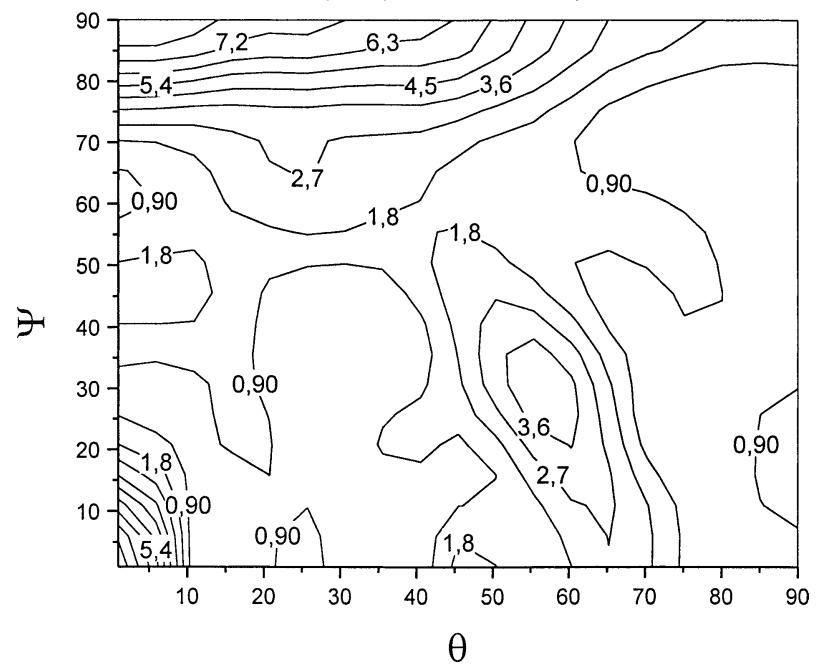

Fig. 9. Sample $(500 \mu \mathrm{m} / \varepsilon=2.1 / \mathrm{IR})$. ODF, section $\Phi=45^{\circ}$. Roe notation.

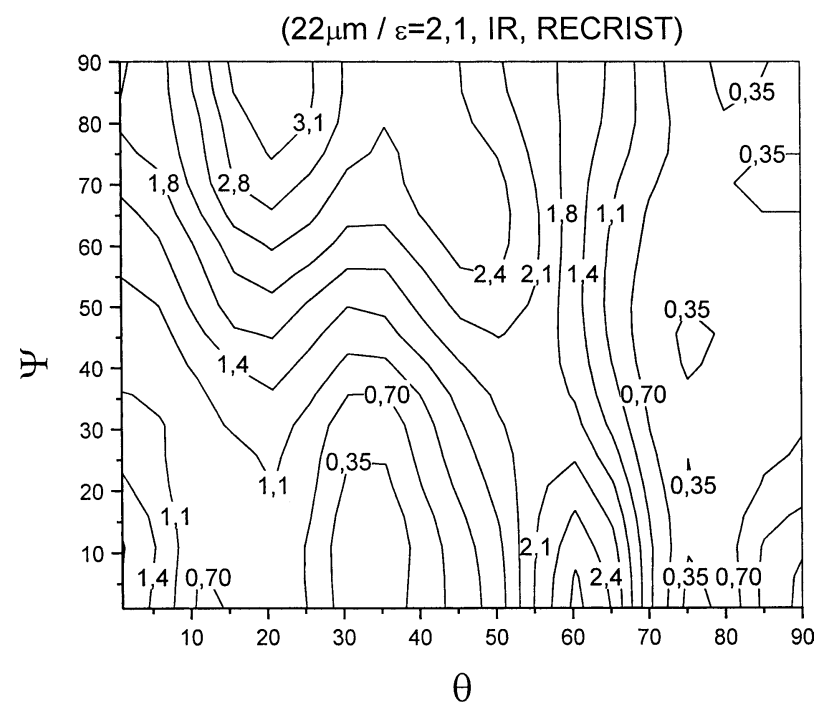

Fig. 10. Sample $\left(22 \mu \mathrm{m} / \varepsilon=2.1 / \mathrm{IR}\right.$, reX). ODF, section $\Phi=45^{\circ}$. Roe notation.

$(125 \mu \mathrm{m} / \varepsilon=2,1, \mathrm{IR}, \mathrm{RECRIST})$

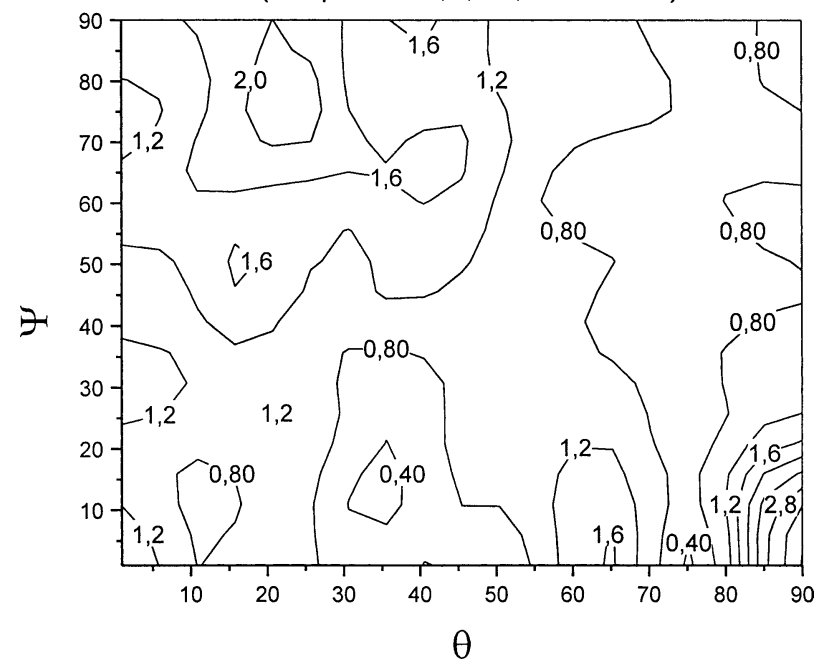

Fig. 11. Sample $(125 \mu \mathrm{m} / \varepsilon=2.1 / \mathrm{IR}, \mathrm{reX})$. ODF, section $\Phi=45^{\circ}$. Roe notation.

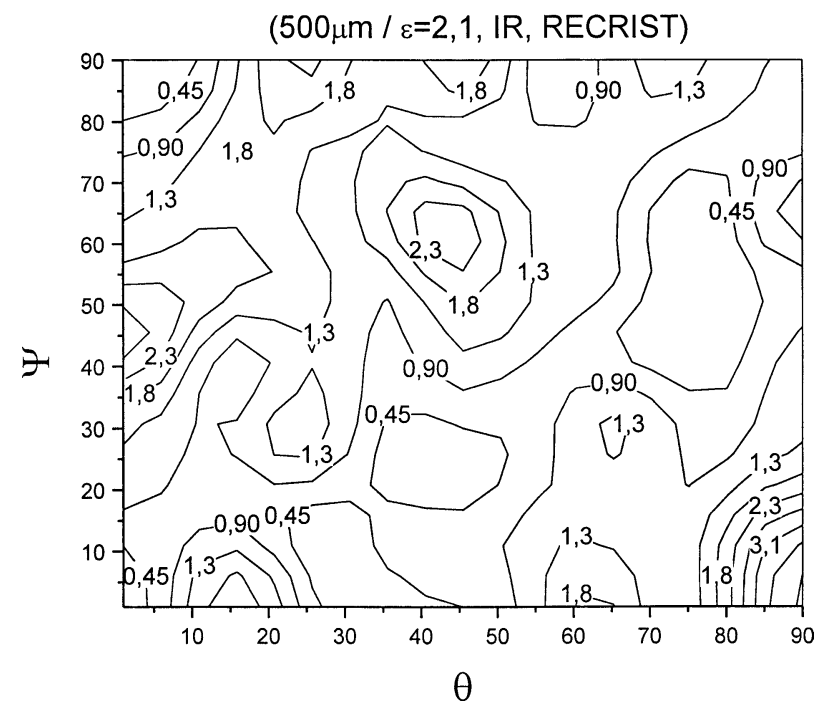

Fig. 12. Sample $\left(500 \mu \mathrm{m} / \varepsilon=2.1 / \mathrm{IR}\right.$, reX). ODF, section $\Phi=45^{\circ}$. Roe notation.

2.1/IR) (Fig. 9) is similar to that of sample $(500 \mu \mathrm{m} / \varepsilon=2.1)$ (Fig. 2).

The sample $(22 \mu \mathrm{m} / \varepsilon=2.1 / \mathrm{IR}$, reX) (Fig. 10) presents as texture components $\{100\}\langle 032\rangle,\{210\}\langle 001\rangle,\{311\}\langle 011\rangle$, $\approx(337)[3 \overline{5} 1]$ and a fiber $\langle 111\rangle / / \mathrm{ND}$, with maximum at $\{111\}\langle 112\rangle$ and $\{111\}\langle 321\rangle$.

The texture of sample $(125 \mu \mathrm{m} / \varepsilon=2.1 / \mathrm{IR}$, reX) (Fig. 11) is very similar to that of sample $(125 \mu \mathrm{m} / \varepsilon=2,1$, reX) (Fig. 5) (same texture components, with similar intensities).

Also the texture of sample $(500 \mu \mathrm{m} / \varepsilon=2.1 / \mathrm{IR}$, reX) (Fig. $12)$ is very similar to the observed for sample (500 $\mu \mathrm{m} / \varepsilon=2.1$, reX) (Fig. 6), showing the same components with similar intensities.

ii) Effect of Hot Band Grain Size on the Recrystallization Texture

The recrystallization texture is strongly influenced by the hot band grain size.

The fiber $\{111\}\langle u v w\rangle$ is always present. High intensity of Goss components occur only for the sample with larger hot band grain size $(125 \mu \mathrm{m}$ and $500 \mu \mathrm{m})$.

The Goss intensity increases just slightly when the hot band grain size increases from $125 \mu \mathrm{m}$ (Figs. 4 and 11) to $500 \mu \mathrm{m}$ (Figs. 5 and 12). Thus, we may conclude that the Goss intensity is not directly related to the surface of grain boundaries, because this area is significantly reduced when grain size increases from 125 to $500 \mu \mathrm{m}$.

It is noteworthy that the component cube-on-face $\{100\}$ $\langle 001\rangle$ appears just for the samples with hot band grain size $500 \mu \mathrm{m}$, a result confirmed for both samples with or without intermediate recovery (respectively, Figs. 12 and 5).

\section{Discussion}

\subsection{The Effect of Hot Band Grain Size on Deformed Structure}

The results here presented show that there is no substantial effect of hot band grain size on the deformation texture. This deformation texture is formed by $\langle 111\rangle / \mathrm{ND}$ and $\langle 110\rangle / / \mathrm{RD}$ fibers (as often experimentally observed, the 
fiber $\langle 110\rangle / / \mathrm{RD}$ is incomplete, because $\{110\}\langle 110\rangle$ components are missing). We detected a trend of increasing intensity of those fibers when the hot band grain size is large $(500 \mu \mathrm{m})$, as is inferred from the textures of the samples $(500 \mu \mathrm{m} / \varepsilon=2.1)$ and $(500 \mu \mathrm{m} / \varepsilon=2.1 / \mathrm{IR}) \quad$ (respectively, Figs. 2 and 9) when compared with those other cold rolled samples (Figs. 1, 3, 7 and 8).

When analysing the microstructure by optical means, evidences of strong strain inhomogeneities were found in the larger grain size samples: some grains showed large number of in-grain shear bands, while others had none. Evidence of grain subdivision were found in the samples with large initial grain sizes: Samples with 5 grains in the thickness of the hot band ended up with 10 to 15 grains in the final $0.5 \mathrm{~mm}$ thickness. As it is very difficult to get EBSD analysis from highly deformed samples, etch pit examination showed single oriented pits in each grain, suggesting homogeneous deformation structure inside each grain, as shown in Fig. 13. It was not possible to find evidence to differentiate between original grain boundaries and grain boundaries from grain subdivision. Due to grain shape change in deformation, even the original grain boundary area increases.

\subsection{The Effect of Hot Band Grain Size on Recrys- tallised Texture}

The recrystallization texture is strongly influenced by the hot band grain size. Thomson established the relation between large hot band grain size and the enhancement of Goss component in 1969. ${ }^{6)}$ Hutchinson and coworkers ${ }^{12-14)}$ also emphasized that the grain size before cold rolling has an important effect on the recrystallization texture and suggested that the occurrence of heterogeneous deformation such as shear bands (that would favour Goss components) tends to be more prominent for large grain size.

A very important detail is that the total surface of grain boundaries is considerably reduced with the increase of grain size, from 125 to $500 \mu \mathrm{m}$. However, the intensities of Goss and fiber $\{111\}\langle u v w\rangle$ is very similar in those two cases (see Figs. 5, 6, 11 and 12). Those data show that the intensity of Goss does not increase continuously with the increase of grain size of hot band (and is not direct a function of grain boundaries area). It seems that, after a given grain size (between 22 and $125 \mu \mathrm{m}$, according with the ac-

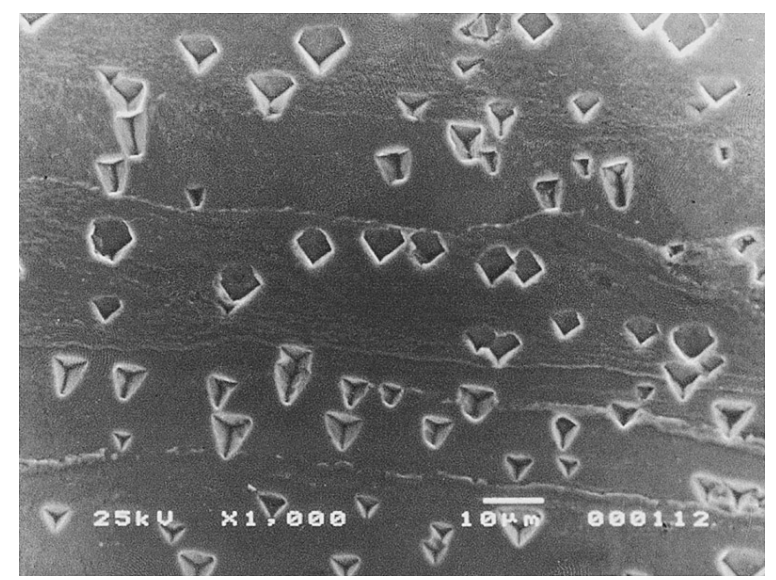

Fig. 13. Etch pits on deformed grains. Sample with grain size $500 \mu \mathrm{m}$ and $\varepsilon=2,1$. Paralel to surface. quired data), the Goss intensity almost does not increase.

\subsection{Effect of Intermediate Annealing}

The results here presented show no apparent effect of intermediate annealing on the final deformed texture, nor in the recrystallized texture. The same texture components are present (Figs. 4 to 6 and 10 to 12), with almost the same intensity.

This is quite different from what Shimanaka and coworkers $^{9)}$ had shown, where an intermediate high temperature anneal could decrease losses and increase permeability in a two stage rolling with $50 \%$ area reduction each. Takashima and co-workers ${ }^{10)}$ have shown that an intermediate annealing led to a significant change in final texture, but only when the amount of recrystallization was around $50 \%$, followed by a final deformation with $\varepsilon=0.12$. Buerger and others ${ }^{11)}$ indicated that a low temperature annealing, where no recrystallization took place, led to another change in texture. Again the final deformation was also low.

It seems that although various techniques of intermediate anneal may improve magnetic properties, the procedure here used, a low temperature recovery treatment followed by a large amount of deformation and final anneal, is not effective.

\subsection{Origin of the Recrystallization Texture Compo- nents Fiber $\{111\}\langle u v w\rangle$ and Goss $\{110\}\langle 001\rangle$}

It has been experimentally observed ${ }^{13,14)}$ that the Goss component $\{110\}\langle 001\rangle$ appears after recrystallization of single crystals with orientation $\{111\}\langle 112\rangle$. But, experiments with single crystals with other orientations did not produce such $\{111\}$ components. ${ }^{15)}$ Thus, it has been postulated that grains with orientation $\{111\}$ would have originated from grain boundaries. ${ }^{15)}$

However, it should be emphasised that the deformed polycrystalline structure is much different from deformed single crystals. Figures $\mathbf{1 4}$ to $\mathbf{1 6}$ show the microstructure of deformed samples from hot bands with grain sizes of 22, 125 e $500 \mu \mathrm{m}$, where different grains show different amount of in-grain shear bands. Thus, the extrapolation of single crystals results ${ }^{14,15)}$ may not be valid for polycrystalline materials, particularly for small grain size.

Nevertheless, it seems there is no better explanation for the appearing of a recrystallization texture consisting of $\{111\}\langle u v w\rangle$ fiber and Goss $\{110\}\langle 001\rangle$ and the above ex-

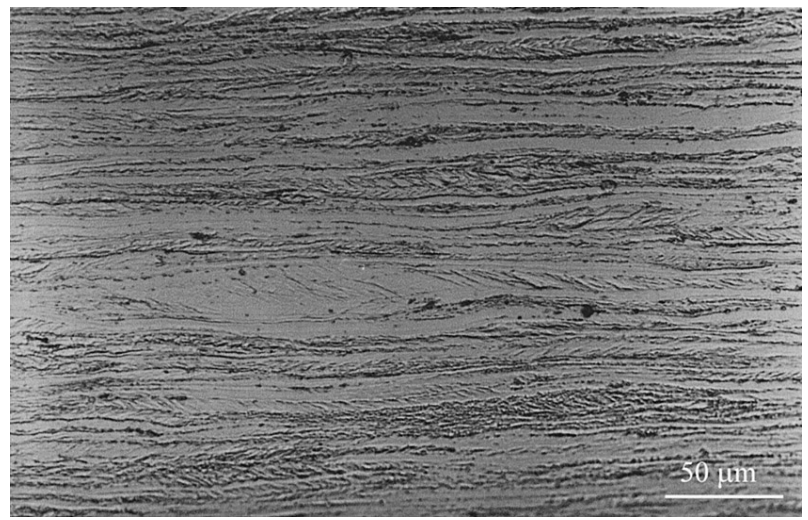

Fig. 14. Sample $(22 \mu \mathrm{m} / \varepsilon=2.1 / \mathrm{IR})$. Optical microscopy. Paralel to surface. 


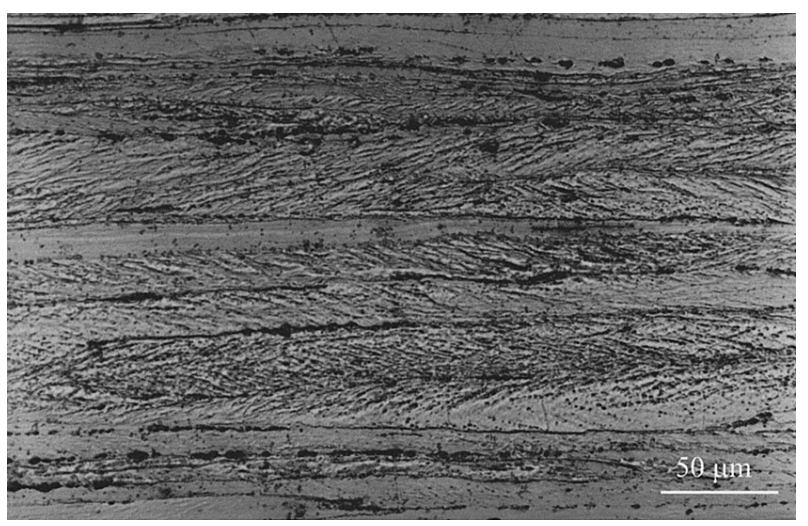

Fig. 15. Sample $(125 \mu \mathrm{m} / \varepsilon=2.1 / \mathrm{IR})$. Optical microscopy. Paralel to surface.

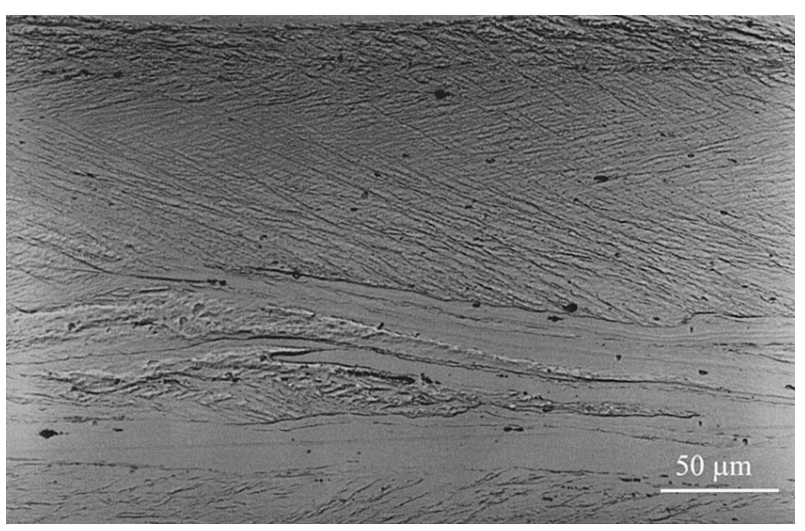

Fig. 16. Sample $(500 \mu \mathrm{m} / \varepsilon=2.1 / \mathrm{IR})$. Optical microscopy. Paralel to surface.

planations ${ }^{15)}$ remain the most accepted.

It is noteworthy to add that Goss components are source of strong magnetic property anisotropy ${ }^{16,17}$ in non-oriented electrical steels and, thus, there is technological interest on the control of the formation of this component during recrystallization.

\subsection{The Recrystallized Grain Size}

The recrystallized structure is considered as the product of primary recrystallization, because grain growth is unlikely at such low temperature and short time (final annealing took place at $700^{\circ} \mathrm{C}, 5 \mathrm{~min}$.). We noted a general trend of decreasing the recrystallized grain size when hot band grain size decreases.

Grain boundaries act as obstacles to dislocation movement. When smaller the grain size, larger the dislocation density. ${ }^{18)}$ Due to the deformation, the region near grain boundaries tends to present higher density of dislocations. For strong reduction levels, those places near grain boundaries became strongly deformed and with remarkable variations of orientation. ${ }^{15)}$

The following reasoning can be applied: smaller grain size before deformation develops higher stored energy, higher is the driving force for recrystallization (greater number of recrystallization nuclei) and smaller tends to be the recrystallized grain size.

An additional complication is the effect of crystallographic orientation. Grains with high Taylor factor tends to

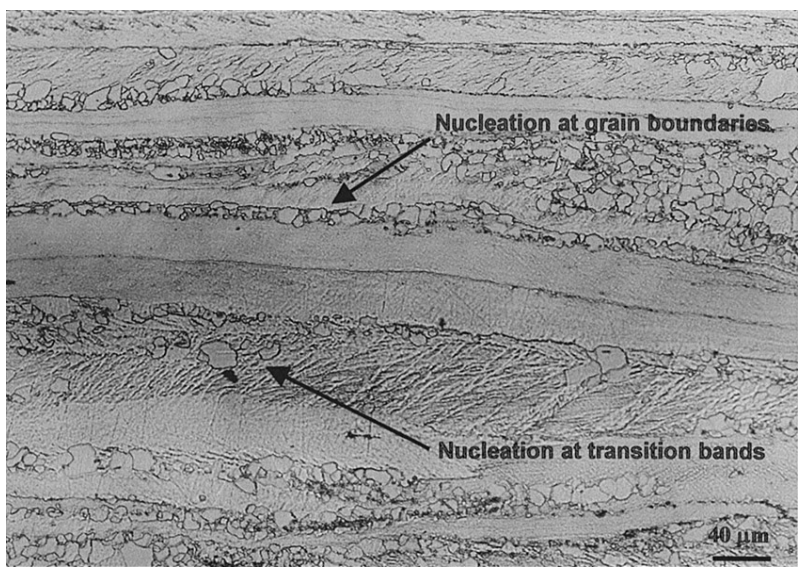

Fig. 17. Recrystallization nuclei in a sample with hot band grain size of $500 \mu \mathrm{m}$, heat treatment $580^{\circ} \mathrm{C} / 5 \mathrm{~min}$ (interrupted recrystallization). Paralel to surface.

present higher density of dislocations and resist more against deformation. Thus, orientations with higher Taylor factor may originate smaller grains after recrystallization.

Grain boundaries are favourable places for nuclei (due to heterogeneous nucleation), and thus an increase on the amount of boundaries tend to result in an increase of the amount of nuclei, reducing also the recrystallized grain size.

Figure 17 indicates that grain boundaries and in-grain shear bands are preferential sites for nucleation in the sample with hot band grain size of $500 \mu \mathrm{m}$, submitted to a short -5 mins-heat treatment at low temperature- $-580^{\circ} \mathrm{C}$. The recrystallization was interrupted, allowing identifying nucleation sites.

\subsection{Clusters of Recrystallized Grains with the Same Orientation}

It was noted that samples with higher hot band grain size $(500 \mu \mathrm{m})$ present clusters of grains with same orientation ${ }^{7,8)}$ after final recrystallization. Those clusters can be easily identified in sections parallel to the surface. It is difficult to observe them in longitudinal sections due to the small thickness of the deformed original grains. The clusters assume lengthened format, elongated in the rolling direction.

Due to plastic deformation the grains lengthen, with the larger dimension parallel to rolling direction. The clusters format suggests that they are occupying the place of the same deformed grain, and each one of those large grains recrystallizes independently.

Only few authors ${ }^{15,19)}$ expressed comments about heterogeneities in the recrystallized structure when the grain size previous to recrystallization is very large. Inagaki ${ }^{15)}$ and Park and coworkers ${ }^{4)}$ confirm that, when the grain size is too large, the grains tend to recrystallize independently.

Pictures shown in Figs. 18 to 20 reveal the microstructure of sample with hot band grain size of $500 \mu \mathrm{m}$, after recrystallization. The data obtained by means of etch-pits was also confirmed by EBSD technique in a SEM. ${ }^{7)}$

It was noted that clusters with Goss orientation $\{110\}$ $\langle 001\rangle$ present small grain size (Fig. 19). This suggests that the Goss clusters had originated from grains with high Taylor factor, supporting the idea that Goss forms on $\{111\}$ 


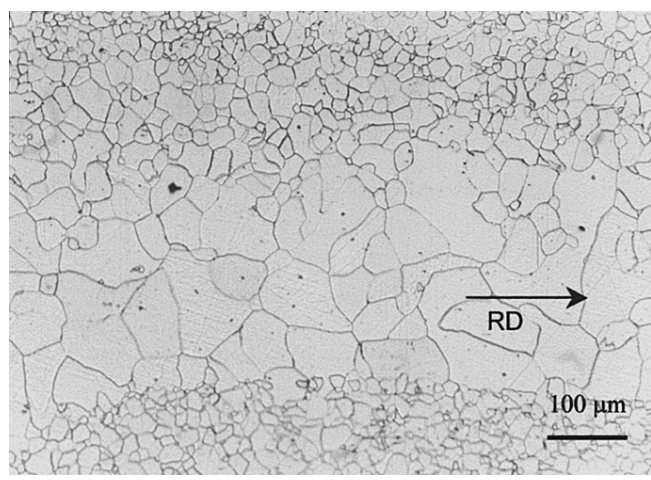

Fig. 18. Sample $(500 \mu \mathrm{m} / \varepsilon=2.1 / \mathrm{IR}$, reX). Clusters of big and small grains. Optical microscopy. Paralel to surface. $\mathrm{RD}=$ rolling direction

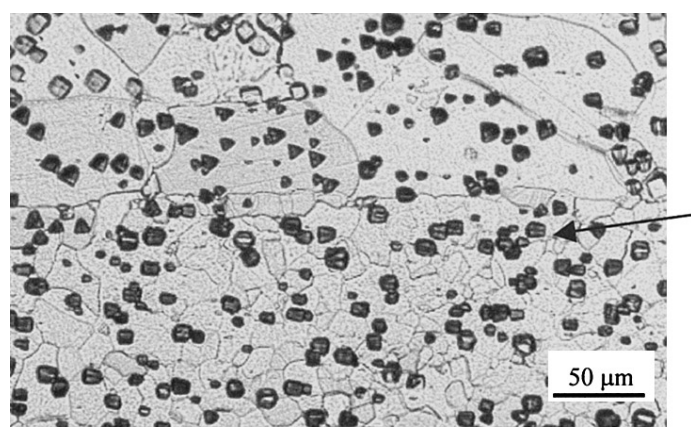

Fig. 19. Sample $(500 \mu \mathrm{m} / \varepsilon=2.1 / \mathrm{IR}$, reX). Etch-pits reveal small recrystallized grains with Goss $\{110\}\langle 001\rangle$ orientation. Optical Microscopy. Paralel to surface.

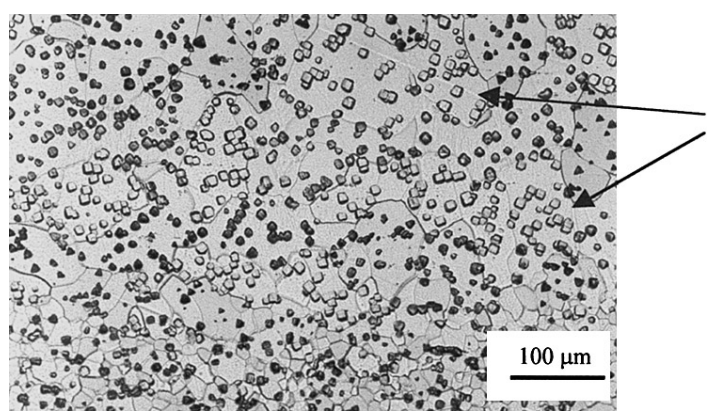

Fig. 20. Sample $(500 \mu \mathrm{m} / \varepsilon=2.1 / \mathrm{IR}$, reX). Note the larger grains with orientation $\{100\}$ revealed by etch-pits. Optical microscopy. Paralel to surface.

deformed grains. ${ }^{12-14)}$ This has been recently experimentally confirmed when EBSD was employed to study a sample where recrystallization was interrupted. ${ }^{20)}$

On the other hand, clusters with cube orientation $\{100\}$ present larger grain size (Fig. 20). This suggests that cube grains formed from grains with low Taylor factor (maybe the component $\{100\}\langle 011\rangle$-"rotated cube"), one of the main components of the deformation texture. ${ }^{19)}$

\section{Conclusions}

The hot band grain size almost does not affect the deformation texture; nevertheless, the recrystallization texture is strongly influenced by that variable. There is no apparent effect of an intermediate recovery (after deformation $\varepsilon=0.7$ annealing at $500^{\circ} \mathrm{C}$ during $1 \mathrm{~h}$ ) on the deformation or recrystallization textures Increasing hot band grain size from 22 to $125 \mu \mathrm{m}$ decreases $\{111\}$ components and increases Goss in the recrystallized state, as it is well known. Further increase to $500 \mu \mathrm{m}$ does not increase Goss, but increases cube on face component. It also originates clusters of grains with similar orientation, each cluster probably coming from one deformed grain. When the hot band grain size is very large $(\sim 500 \mu \mathrm{m})$ the deformed grains tend to recrystallize independently, originating regions (clusters) of grains with same orientation.

\section{Acknowledgements}

MF de Campos thanks CAPES and FAPESP (Proc. 01/09122-4). The authors also thank FAPESP Proc. 99/10796-8). The assistance of Vicente I dos Santos is gratefully acknowledged.

\section{REFERENCES}

1) H. Yashiki and T. Kaneko: J. Magn. Magn. Mater., 112 (1992), 200

2) T. Waeckerlé, M. Mekhiche and C. Brun: J. Magn. Magn. Mater, 133 (1994), 195.

3) C.-K. Hou: J. Magn. Magn. Mater, 162 (1996), 291

4) J. Park, J. A. Szpunar and K. Han: Mater. Sci. Forum, 408-412 (2002), 1257

5) R. K. Ray, J. J. Jonas and R. E. Hook: Int. Mater. Rev., 39 (1994), 129.

6) T. R. Thomson: Interfaces Conference, ed. by R. C. Gifkins, The Australian Institute of Metals, Butterworths, London, (1969), 374.

7) R. Takanohashi, F. J. G. Landgraf, M. F. de Campos, I. G. S Falleiros, A. L. Pinto and C. S. da C. Viana: Proc. of $21^{\circ}$ Riso Int. Symp. on Materials Science, Riso, Roskilde, Denmark, (2000), 601.

8) F. J. G. Landgraf, R. Takanohashi, F. C. Chagas, M. F. de Campos and I. G. S. Falleiros: J. Magn. Magn. Mater., 215-216 (2000), 92.

9) H. Shimanaka, Y. Ito, T. Irie, K. Matsumura, H. Nakamura and Y. Shono: Proc. of Energy Efficient Electrical Steels Conference, TMSAIME, Metals Park, Ohio, (1981), 193

10) M. Takashima, M. Komatsubara and N. Morito: ISIJ Int., 37 (1997), 1263.

11) R. Buerger, G. Lehmann, W. Lindner, H. Wich and J. Wleting: Non oriented electrical steel and fabrication method, European Patent EP 0431502 A2, (1991).

12) W. B. Hutchinson and K. Ushioda: Scand. J. Metall., 13 (1984), 269.

13) T. Haratani, W. B. Hutchinson, I. L. Dillamore and P. Bate: Met. Sci., 18 (1984), 57.

14) K. Ushioda and W. B. Hutchinson: ISIJ Int., 29 (1989), 862.

15) H. Inagaki: ISIJ Int., 34 (1994), 313.

16) M. Emura, M. F. de Campos, F. J. G. Landgraf and J. C. Teixeira: J. Magn. Magn. Mater, 226-230 (2001), 1524.

17) M. F. de Campos, F. J. G. Landgraf and A. P. Tschiptschin: J. Magn Magn. Mater, 226-230 (2001), 1536

18) A. S. Keh and S. Weissmann: Electron Microscopy and the Strength of Crystals, ed. by G. Thomas and J. Washburn, Interscience, New York, (1963), 231.

19) B. Hutchinson: Philos. Trans. R. Soc. (London) A, 357 (1999), 1471

20) R. Takanohashi and F. J. G. Landgraf: unpublished. 